\title{
CONTROVÉRSIAS SOCIOCIENTÍFICAS NA WEB 2.0: QUAIS POTENCIALIDADES EDUCATIVAS ENVOLVENDO RACISMOS E MACHISMOS?
}

\author{
Socio-Scientific Controversies on Web 2: What Educational Possibilities Exist Regarding \\ Racism and Machismo?
}

\author{
Emanuella Geovana Magalhães de Souza ${ }^{1}$ \\ Francis Musa Boakari ${ }^{2}$ \\ Francilene Brito da Silva ${ }^{3}$
}

\begin{abstract}
Resumo: Ainda no século XXI com as tecnologias digitais, a necessidade de buscar alternativas para melhor abordar e principalmente aprender com assuntos polêmicos como os machismos e racismos brasileiros de modo interseccional, desencadeou a seguinte indagação: Quais potencialidades educativas podem ser encontradas na utilização da Web 2.0 na discussão de controvérsias sociocientíficas (CSC), em especial nas interseccionalidades entre raça e gênero? Deste modo, com o presente artigo, através dos temas: educações, intersecção de raça e gênero, internet e CSC, objetivou-se identificar e discutir as potencialidades educativas (ensinar-aprender-questionar) da Web 2.0 na abordagem de CSC em especial, as interseccionalidades entre raça e gênero. Para tanto, discorreu-se sobre pesquisas relacionadas às CSC mediadas pelas tecnologias digitais, bem como, a utilização do YouTube, mídia social de compartilhamento de vídeos. Para a base conceitual-reflexiva destacaram-se autoras/es como, Kimberlé Crenshaw (2002), Sueli Carneiro (2005), Tim O'Reilly (2005), Boaventura de Sousa Santos (2007), Pedro Reis (2006) entre outras/os. Concluiu-se que a abordagem de CSC em espaços digitais está repleta de potencialidades para educar, pois viabiliza enxergar todas as pessoas como protagonistas das suas próprias existências numa coletividade dinâmica, proporcionando resistências e autonomias para provocar problematizações, vislumbrando mudanças em um contexto racista e machista, como o brasileiro.
\end{abstract}

Palavras-chave: Controvérsias Sociocientíficas. Internet. Interseccionalidade Raça-Gênero.

\footnotetext{
${ }^{1}$ Doutoranda em Educação pelo Programa de Pós - Graduação em Educação da Universidade Federal do Piauí (PPGED - UFPI). Na mesma instituição obteve o título de Mestra em Educação. Integrante do Núcleo de Estudos e Pesquisas Roda Griô-GEAfro: Gênero, Educação e Afrodescendência (UFPI). E-mail: slts.emanuella@gmail.com. Currículo Lattes: http://lattes.cnpq.br/2709397814332686. ORCID: https://orcid.org/0000-0002-6173-1355.

2 Pós-doutorado na Auburn University; Professor da Universidade Federal do Piauí, atuando no Departamento de
Fundamentos da Educação (DEFE) e Programa de Pós-Graduação em Educação (PPGED). Desenvolve trabalhos
referentes às questões raciais e das afrodescendências, e coordena o Núcleo de Estudos e Pesquisas Roda
Griô-GEAfro: Gênero, Educação e Afrodescendência (UFPI). E-mail: musabuakei@yahoo.com. Currículo
Lattes: http://lattes.cnpq.br/8595766452722585. ORCID: https://orcid.org/0000-0002-5786-2387.

${ }^{3}$ Doutora em Educação (UERJ); Mestre em Educação (UFPI); Professora da Universidade Federal do Piauí; uma das líderes-pesquisadora do Núcleo de Estudos e Pesquisas Roda Griô-GEAfro: Gênero, Educação e Afrodescendência (UFPI) e pesquisadora do Grupo de Pesquisa Culturas e Identidades no Cotidiano (UERJ). Estuda temas sobre Educação e Diversidade a partir de: Arte e Afrodescendência como Narrativas (escritas, orais e imagéticas) decoloniais e cotidianas. E-mail: artlenha@yahoo.com.br. Currículo Lattes: http://lattes.cnpq.br/9154219626884328. ORCID: https://orcid.org/0000-0001-9655-6633.
} 
Abstract: The need for alternative ways that can effectively help us approach and especially learn more from controversial issues like Brazilian machismo and racism, despite the digital technologies of the 21 st century, triggered the following question - What educational possibilities are available from using Web 2.0 to promote discussions related to socioscientific controversies like machismo and racism in their intersectionalities? The authors of this article, focused on themes like education, race-gender intersectionality, internet and controversies in socio-scientific matters, to identify and discuss the educational potentials of Web 2.0 in teaching-learning-asking questions related to controversial issues, especially those involving race and gender intersectionalities. Research reports about socio-scientific controversies using digital technologies including YouTube, as social media for sharing videos, were also treated. Kimberly Crenshaw (2002), Sueli Carneiro (2005), Tim O'Reilly (2005), Boaventura de Sousa Santos (2007), Pedro Reis (2006) and others alike, provided the needed theoretical support. Analyses helped conclude that the approach to controversial topics in virtual spaces, while providing rich educational venues, made it possible for more people to become protagonists of their own existence, and similarly, be resistant and independent in problematizing different issues to the extent that they could even bring about changes in a racist and sexist context such as the one we live in Brazilian society.

Keywords: Socio-scientific Controversies. Internet. Race-Gender Intersectionality.

\section{Iniciando a conversa}

Não há como desenvolver uma discussão acerca das controvérsias sociocientíficas (CSC) sem reconhecer o estrago global, sem precedentes, causado pela COVID-19 como consequência marcante de combates, discordâncias e acirradas divergências ideológicas nacionalistas, em tempos recentes, tudo alicerçado em discriminações-racimos-desigualdades seculares. CSC são reais nos seus resultados/efeitos em políticas públicas desvirtuadas, contra o povo, e toda a sociedade humana no final das contas. (Autores do texto).

Este texto trata das possibilidades da utilização da Web 2.0 na abordagem e discussão de controvérsias sociocientíficas, em especial da intersecção entre raça e gênero, mas, não poderia servir de reflexão válida, se deixasse de mencionar que o desenvolvimento de seu conteúdo, iniciado antes da quarentena, devido à COVID-19 - doença causada pelo Coronavírus SARS-CoV-2 (BRASIL, s/d) - continuou durante este período de experiências nunca vividas antes. Como pano de fundo, as expectativas de uma pós-pandemia como período imprevisível, imaginável ou inimaginável, nos provoca a repensar até mesmo um tema como este.

Com esta situação e ausência de política sanitária para a população que sofre com as intersecções aqui pontuadas, bem como, com os conhecimentos e vivências conquistados até aqui, apresentamos a ideia de que as questões relacionadas às discriminações raciais e de gênero, de maneira conectada, ainda causam discussões conflitantes, uma vez que inexiste consenso referente aos machismos e racismos brasileiros. E, por isso mesmo, passa a existir a necessidade de se encontrar alternativas para minimizar essa carência de saber elaborado sobre o assunto ou provocar rupturas em tal realidade como estímulo à produção de novos conhecimentos que possam preencher os vazios sobre o conteúdo em pauta.

No emaranhado de informações e conflitos que aparecem nos espaços digitais procuramos, neste estudo, identificar e discutir as potencialidades educativas da utilização da Web 2.0 no tratamento de questões relacionadas às interseccionalidades entre raça e gênero como controvérsias sociocientíficas. Diante dessa decisão, fazemos a seguinte indagação: quais potencialidades educativas podem ser encontradas na utilização da $\mathrm{Web} 2.0$ na discussão 
de controvérsias sociocientíficas, em especial nas interseccionalidades entre raça e gênero? Partindo dessa questão, discutimos algumas das potencialidades educativas da Web 2.0 na abordagem de CSC, baseando-se em pesquisas já realizadas nestes âmbitos. Além disso, discutimos outras possibilidades-meios de realizar essa abordagem, como a utilização do YouTube, mídia social de compartilhamento de vídeos, por exemplo.

Partindo desta indagação, procuramos evidenciar as ligações entre a abordagem das controvérsias sociocientíficas, que trataremos aqui com a sigla CSC, a partir da Web 2.0 focalizando nas intersecções entre raça e gênero, na tentativa de reconhecer que o desvelamento das realidades machistas e racistas da sociedade brasileira pode ser fomentado e encorajado nos espaços digitais e também na discussão de CSC, que atuando de maneira conjunta engendram para a construção de educações questionadoras e problematizadoras. Estas potencializam reflexões críticas e aprendizagens sobre conhecimentos historicamente negados e silenciados, mais do que isso, estamos argumentando que as discussões das interseccionalidades entre gênero e raça como CSC através da utilização da Web 2.0, proporciona uma educação mais humana, diferenciada e criativa, embora correndo riscos contrários.

A conectividade, a interação, a explosão de informações, bem como, a criação e consumo de conteúdos ocasionados pela internet, são marcas e características bastante vivenciadas nos tempos atuais. As empresas em geral, as instituições formais e informais da sociedade, incluindo a Educação Escolar, são usuárias costumeiras/habituais da internet e, em especial, as crianças e adolescentes desta época digital que desde cedo entram em contato com essas tecnologias. Logo, diante da realidade que se apresenta, se faz importante e urgentemente necessário, compreender as potencialidades educativas proporcionadas pelos espaços digitais, no que se refere às questões sociais, científicas e tecnológicas que invadem nossa realidade, principalmente neste momento de pandemia da doença COVID-19 ocasionada pelo vírus SARS-CoV-2 (Síndrome Respiratória Aguda Grave - Coronavírus 2), que alterou as formas de socialização, educação e trabalho. As pessoas tiveram que aprender a evitar aglomerações se conectando mais através das redes sociais; as escolas começaram a inserir o ensino remoto, com a utilização de aulas transmitidas ao vivo ou gravadas; assim como, as empresas e instituições formais e informais que precisaram se adaptar aos recursos da internet.

Apesar das oportunidades evidenciadas, o contexto pandêmico escancarou a desigualdade de acesso à internet da população brasileira afrodescendente já existente. Segundo o Informativo, Desigualdades Sociais por Cor ou Raça no Brasil, do Instituto Brasileiro de Geografia e Estatística (IBGE, 2019), o acesso à internet por pessoas entre 15 e 29 anos, corresponde $92,5 \%$ de brancos e $84,3 \%$ de pretos e pardos, enquanto o uso do microcomputador para acessar a internet é de $61,6 \%$ entre brancos e $39,6 \%$ entre pretos e pardos. Soma-se a isso, o fato de ser esta a população que mais tem sido afetada pelo vírus em decorrência de suas condições precárias de vida, como trabalho e moradia, o que demonstra as imbricações e conexões entre o neoliberalismo e a crise sanitária, de raça, de pobreza, de saúde pública e de Estado (GOMES, 2020). As desigualdades já existentes, as quais antes pareciam ser ignoradas ou camufladas, estão sendo escancaradas com a pandemia, trazendo à tona as mazelas de uma sociedade secularmente adoecida em sua humanidade.

Dentre essas questões relacionadas às discriminações raciais e de gênero que assolam a humanidade, destacamos a interseccionalidade entre gênero e raça, cujas categorias se constituem como constructos sociais. A categoria raça é biologicamente infundada, porém o conceito "sociologizado" de raças superiores e inferiores como base para classificar as 
pessoas em termos da herança genética, ou traços fisionômicos, de genótipos ou fenótipos ainda são constantes nas relações sociais. O que estamos colocando em discussão não é a raça biológica, mas a racialização das relações sociais, que provocam hierarquias entre sujeitos e viabilizam "a dificuldade de combater o nosso preconceito, que em certo sentido tem, pelo fato de ser variável, enorme e vantajosa invisibilidade... acabamos por desenvolver o preconceito de ter preconceito [...]" (DAMATTA, 1986, p. 43). O mesmo ocorre com a categoria gênero, fruto de construções sociais que são incansavelmente remodeladas para garantir estas hierarquias. Colling (2015) enfatiza que o corpo feminino é resultado de "práticas e discursos" e, por isso, trata-se de um "efeito histórico", ressaltando que a categoria gênero, foi empregada como forma de questionar a "condição de inferioridade" da mulher a aspectos naturais e biológicos, enfatizando outros aspectos como os sociais e políticos.

As discriminações referentes às categorias construídas de gênero e raça estão conectadas, e ao contrário do que se costuma pensar, não acontecem de forma isoladas e/ou separadas, mas atuam de maneira conjunta, se cruzando, se inter-relacionando e influenciando continuamente um e outro. Essas questões relacionadas à raça e ao gênero estão sendo cada vez mais discutidas e problematizadas, principalmente em razão das potencialidades de criação e difusão de conteúdo proporcionado pela internet. Todavia, tais questões ainda geram desentendimentos, e por vezes, não são compreendidas de maneira coerente e devidamente analisadas. Afinal de contas, vivemos em uma sociedade que, com facilidade e através do discurso competente, ainda encobre a existência do racismo e naturaliza as desigualdades sociais entre homens e mulheres.

Percebemos que as inquietações relacionadas com as discriminações interseccionadas entre raça e gênero, uma vez propulsionadas por este ou aquele fator, mas continuamente interagindo entre si, são controvérsias sociocientíficas. As CSC podem ser geradas de implicações sociais, morais, religiosas, ambientais e/ou econômicas, nos quais a sociedade se encontra em discordância, sem consenso, defendendo e apoiando soluções conflitantes (KRUPCZAK; AIRES, 2019; KRUPCZAK; AIRES; REIS, 2020). Questões relacionadas ao racismo, discriminação de gênero, ainda causam discussões discordantes com pontos de vistas diferentes, apoiados em causas biológicas, aspectos sociais e culturais. Vale ressaltar que estes posicionamentos e as ideias/ideologias fundantes são dinâmicos e até modificações de conteúdo poderiam acontecer.

Para não findar as discussões e pensando no caráter dinâmico das CSC e da utilização da Web 2.0, propomos discorrer sobre os caminhos percorridos na pesquisa e em seguida, tratamos das interseccionalidades entre raça e gênero, apresentando o epistemicídio, discutido por Carneiro (2005), como fator estruturante das opressões raciais e de gênero, além de explicarmos o que são controvérsias sociocientíficas. Prosseguindo, discutimos algumas possibilidades da Web 2.0, partindo de pesquisas realizadas por Santo e Reis (2013), bem como, por Boakari e Souza (2019). Discorremos também sobre as alternativas educativas (ensinar-aprender-questionar) proporcionadas pelo YouTube a partir de dois vídeos, o primeiro realizado por Gabi Oliveira (2016), formada em Comunicação Social (Universidade do Estado do Rio de Janeiro - UERJ) e responsável pelo canal DePretas. No vídeo Negra de pele escura part. Soul Vaidosa, Gabi Oliveira conversa com a, também youtuber, Alexandra Ravelli. O segundo vídeo - Empoderamento Estético e Consciência Racial - faz parte do canal Afro e afins, da youtuber Nátaly Neri (2017), cientista social formada e moradora da cidade de São Paulo. Por último, tecemos algumas considerações (in)conclusivas para continuarmos aprendendo, refletindo, perguntando e pesquisando. Ao final desta pesquisa estão elencadas algumas sugestões, reflexões e respostas continuadas sobre as potencialidades 
educativas encontradas na utilização da Web 2.0 quando se discute controvérsias sociocientíficas, em especial nas interseccionalidades entre raça e gênero.

\section{Caminhos percorridos - Caminhos metodológicos}

A fundamentação teórica foi construída a partir de estudos relacionados à cibercultura, controvérsias sociocientíficas e interseccionalidade entre raça e gênero, e algumas/alguns autoras/es como Edméa Santos (2015) e Couto (2014), ajudaram nesse diálogo, para tratar, em especial, sobre a Web 2.0 no que se refere às suas características e possibilidades. Em relação às CSC, os estudos de Reis (2006); Santo e Reis (2013); Krupczak e Aires (2019) foram essenciais para compreender como se operam tais questões em contextos sociais e escolares. Dialogamos também com Crenshaw (2002), Carneiro (2005), Quijano (2005), Boaventura de Sousa Santos (2007) para discorrer sobre as interseccionalidades entre raça e gênero e a construção das desigualdades e silenciamentos em relação às mulheres afrodescendentes. No decorrer do estudo outras/os autoras/es foram chamadas/os para esse diálogo nos ajudando a entender/compreender/contextualizar e problematizar as questões em pauta nesta pesquisa.

A abordagem utilizada foi a qualitativa, partindo das orientações de Flick (2013) sobre pesquisa, análise de documentos e interações online, enfatizando estudos que abordam a internet como tema e/ou instrumento de pesquisa. No nosso caso, a internet é tanto tema principal como instrumento, afinal, discorremos sobre as possibilidades educativas da Web 2.0 no tratamento das questões interseccionais entre raça e gênero como controvérsias sociocientíficas, além de analisarmos o conteúdo da mídia social YouTube para exemplificar as possibilidades da $\mathrm{Web} 2.0$.

A escolha do canal partiu de informações disponibilizadas pelo site Geledés, em que Terto (2016) indicou 12 nomes de youtubers afrodescendentes que tratavam de racismos, machismos, bem como da invisibilidade e falta das experiências e narrativas pessoais de mulheres deste grupo em vários espaços da sociedade. Os nomes apontados foram: Gabi de Oliveira, com o canal DePretas; Nátaly Neri com seu canal Afros e Afins; Xan Ravelli, dona do canal Sou Vaidosa; Lorena Monique com o canal Neggata; Joyce Geravaes que criou o canal Joyce Show; Regianne Rosa dona do canal Coisas de Preta; Patrícia Rammos idealizadora do canal Um Abadá Pra Cada Dia; Jacy July com o canal que leva o seu nome na plataforma; Tatiane Sacramento com o canal Tati Sacramento, e por fim Aline Custódio com o canal Preta Aline Custódio (TERTO, 2016). Dentre esses canais escolhemos o primeiro e o segundo, utilizando como critério o número de inscritos no canal até janeiro de 2021, a saber, 629 e 742 mil inscritos respectivamente.

Escolhemos um vídeo de cada canal (DePretas e Afros e Afins), utilizando como critério, a sua realização nos últimos cinco anos. Outro critério foi que o conteúdo priorizasse as experiências e narrativas relacionadas aos racismos e machismos vivenciados pelas próprias youtubers. Optamos por uma abordagem qualitativa com análise de conteúdo (FLICK, 2013), onde utilizamos dois processos que Rose (2002) definiu como análise de textos audiovisuais que consiste na translação (transcrição das informações), na codificação baseada em um referencial teórico e na análise preliminar dos dados resultantes. Nos próximos tópicos, depois de discutir raça e gênero como temas interseccionais controversos, encontram-se os diálogos com outras/os autoras/es, bem como, a discussão sobre os vídeos acima descritos, de maneira interconectada. 


\section{Intersecções de raça e gênero: discutindo controvérsias sociocientíficas}

Controvérsias estão relacionadas a disputas, conflitos e opiniões diferentes enquanto que as controvérsias sociocientíficas de acordo com Krupczak e Aires são "disputas relacionadas aos benefícios e malefícios da aplicação de determinadas teorias e Tecnologias, envolvendo questões éticas e morais" (2019, p. 278). Se as CSC envolvem disputas, temos um jogo de poder com opiniões e argumentos diferenciados, em situação de conflito não apenas entre os/as cientistas e estudiosos/as, mas também, dentro da sociedade. Sobre isso, Reis menciona que as CSC são: "[...] questões relativas às interações entre ciência, tecnologia e sociedade (nomeadamente, as polêmicas despoletadas pelos eventuais impactos sociais de inovações científicas e tecnológicas), que dividem tanto a comunidade científica como a sociedade em geral" (2006, p. 66).

As discussões, explicações, interpretações e possíveis aplicações de ideias, opiniões, argumentações, utilização de diversas fontes e o incentivo a pesquisa são proporcionadas pelas controvérsias sociocientíficas. Esse tipo de abordagem para problematizar determinados assuntos com crianças e jovens parece ser enriquecedor, já que garante o contato com conhecimentos diversificados. Isso pode ser evidenciado com os acontecimentos recentes em decorrência da pandemia da COVID-19. Aqui percebemos uma expansão do negacionismo científico e dos movimentos anticiência, muitas vezes, provocados pelas "fake news", que são informações falsas e infundadas, disseminadas principalmente por meio das redes sociais. Tais questões envolvem toda a sociedade gerando disputas e polêmicas, como exemplo, o uso de determinados remédios para tratamento e prevenção do novo Coronavírus sem nenhum tipo de pesquisa ou comprovação científica; as polêmicas envolvendo a adoção ou não do isolamento social e os movimentos que apoiam a não vacinação.

Essas questões polêmicas, que são CSC poderiam ser analisadas e discutidas por todos/as e principalmente pelos/as professores/as, tendo as redes sociais como aliadas e/ou recursos pedagógicos, uma vez que muitas/os cientistas têm utilizado desses espaços para divulgar informações e pesquisas de maneira mais acessível e de fácil entendimento para o público em geral, como aponta a matéria feita por Silveira (2021), no portal de notícias $B B C$ News: "Em reação ao negacionismo, pesquisadores levam 'ciência descomplicada' às redes sociais". O que esses/as cientistas estão realizando demonstra as possibilidades educativas das CSC por meio das redes sociais, ao mesmo tempo em que evidencia os dois lados da mesma moeda em relação às redes sociais, que podem servir para disseminar mentiras ou desvelar a realidade e incentivar a pesquisa e a busca por diferentes conhecimentos. Assim, na tentativa de discorrer sobre as potencialidades educativas das CSC, Krupczak e Aires ressaltam algumas contribuições nas aulas de Ciências:

[...] os alunos são defrontados com opiniões e experiências diferentes das suas, sendo obrigados a negociar a resolução dos conflitos e a melhorar seus argumentos. Com isso, os estudantes também aprendem que existe uma diversidade de compreensões, que podem alterar-se com o tempo, e que as minorias e os diferentes devem ser respeitados. (KRUPCZAK; AIRES, 2019, p. 280).

Os conhecimentos na sociedade ocidental são hierarquizados, divididos e colocados numa balança, medindo sua pretensa superioridade e inferioridade. Secularmente alguns grupos foram excluídos e inferiorizados, tanto no que se refere às suas características físicas como também às suas produções culturais e de conhecimentos. Carneiro (2005) denomina essa configuração como epistemicídio. Ideologia e prática que anula não somente os 
conhecimentos não-europeus, mas também, ainda mais pernicioso, é aceitação de atitudes que inferiorizam e criam impotências criativas; suicídios culturais e espirituais, em prol do poder não explicitado ou explícito.

São tentativas de colocar os conhecimentos e nossa própria humanidade, enquanto mulheres e homens afrodescendentes, por exemplo, como inexistente, como bem explicou Santos (2007) ao dizer que o pensamento moderno é abissal, separado radicalmente por uma linha invisível que distingue a realidade social em "desse lado da linha" e "do outro lado da linha". Sendo o outro lado da linha considerado inexistente, e por isso, excluído. Santos (2007) ainda informa que a principal característica do pensamento abissal é a não possibilidade de copresença dos dois lados da linha. Lançam-se aqui as bases do epistemicídio, que se trata justamente da valorização do conhecimento produzido pelo "Norte global" que corresponde ao "desse lado da linha", ao mesmo tempo em que forja a não existência dos conhecimentos produzidos pelo "Sul global", o nosso lado da linha. É neste último lado, que se delimitou, preconceituosamente, de conhecimentos de menor valor, ou seja, apenas os saberes de "senso comum", como as "crenças" e as "magias".

Neste mesmo raciocínio, que se instaura erroneamente, aquilo considerado como conhecimento "universal", produzido por aqueles pertencentes ao Norte global, em contrapartida ao conhecimento denominado de "local", realizado pelo Sul global, quando na verdade, como ensina Mignolo (2007) todo pensamento é localizado, particular e histórico. Latour (1994) ao defender uma antropologia simétrica, que busca a aproximação e a coexistência entre os conhecimentos e os mundos, propõe a necessidade de ultrapassar a separação entre "Nós e Eles". Sendo o primeiro, constituído pelo ocidente, detentor das técnicas para apreender a realidade e "eles" que representam as "outras culturas", que internalizam e absorvem essa realidade. A assimetria entre natureza e cultura apontada por Latour (1994), que conduziu a constituição da ciência, colabora para as divisões invisíveis propostas por Santos (2007), explicadas anteriormente.

Essa configuração social tem relações com o colonialismo, onde a ideia de raça ajudou tanto no fortalecimento desse processo político de autonegação e subjugação como também para legitimar a dominação e inferiorização dos povos dominados pelos colonizadores europeus, como aponta Quijano: “[...] os povos conquistados e dominados foram postos numa situação natural de inferioridade, e consequentemente também seus traços fenotípicos, bem como suas descobertas mentais e culturais" (2005, p. 118). O autor ainda explica que a ideia de raça foi arquitetada a partir do uso das diferenças fenotípicas existentes entre colonizadores e conquistados, fundadas por estruturas biologizadas, mas, de fato hierarquizantes, o que produziu identidades novas, como "índios, negros e mestiços" e redefiniu outras, como "europeu, espanhol, português", o branco superior. O que antes se tratava apenas de uma procedência geográfica com consequências adaptativas, passou a ter conotação racial, para fins classificatórios, justificando as discriminações. Tais identidades foram forjadas em relações de dominação, ou seja, “[...] foram associadas às hierarquias, lugares e papéis sociais correspondentes, com constitutivas delas, e, consequentemente, ao padrão de dominação que se impunha" (QUIJANO, 2005, p. 117). Definindo de maneira imposta e nociva, papéis e lugares na sociedade. De um lado, os povos conquistados, inferiorizados, desvalorizados e desumanizados, e de outro, os conquistadores, que se apresentavam como ideal a ser seguido, gozando de inúmeros privilégios.

O critério racial, além de apoiar na divisão e classificação das pessoas, também tratou de justificar a inferiorização dos traços fenotípicos, produções culturais e os conhecimentos dos povos colonizados. Essa dupla inferiorização e desqualificação que Carneiro (2005) 
denominou de epistemicídio, faz lembrar que "[...] não é possível desqualificar as formas de conhecimento dos povos dominados sem desqualificá-los também, individual e coletivamente, como sujeitos cognoscentes" (CARNEIRO, 2005, p. 97). Assim, o epistemicídio configura-se como um modo de ser-pensar-agir capaz de matar povos porque a sua competência como sujeitos de sua própria história é negada, substituída por ideologias e práticas de desvalorização e autonegação.

Nas relações entre povos europeus e outros povos, esta matança aconteceu não somente na escravização de sem-número de africanas/os e seus descendentes durante séculos, mas também, de outros atos de genocídio no continente africano, ainda no século XX. Exemplos incluem atrocidades como o "primeiro genocídio do século 20" praticado pelos alemães contra os povos herero e nama do atual Namíbia, sul da África de 1904-1907 (MARTINS, 2017). Também, houve atos genocídios incluindo "amputações, estupros e assassinatos" sumários de milhões de homens, mulheres e crianças na, hoje República Democrática do Congo, cometidos pelos belgas do chamado Rei Leopoldo (DUARTE, 2020). Foram crimes contra a humanidade, até hoje não reconhecidos como tais, e largamente ausentes das literaturas e historiografias de África (MACEDO, 2008). Estamos discutindo o epistemicídio, mas é importante lembrar, também, que esta desumanização chegou e ainda chega, em muitos casos, até a matança física de outras pessoas, indivíduos definidos como diferentes, e assim, presumidos como sendo seres menos que humanos como mostram estes exemplos aqui. Neste contexto, as ideias de raças humanas superiores e inferiores continuam sendo questionadas e refutadas, todavia, ainda prevalece a "racialidade" nas relações sociais brasileiras de maneira a excluir, estigmatizar, discriminar, desumanizar apenas o lado subalternizado, ou seja, das mulheres e homens afrodescendentes, indígenas e outros grupos como esses historicamente excluídos.

As relações raciais desiguais presentes na sociedade brasileira são camufladas através da falsa concepção e ideologia eurocentrada: a democracia racial. Essa ideologia considera que todos/as são iguais, com igual acesso às oportunidades-bens sociais por causa da miscigenação, excluindo assim, qualquer tipo de discriminação, violência e racismo. Há dados atuais que contradizem este discurso da igualdade na sociedade brasileira. O portal de notícias G1 divulgou, em meados de abril de 2020, ainda no início da pandemia, que "A Covid-19 tem se mostrado mais letal entre negros do que entre brancos segundo dados do Ministério da Saúde". De acordo com esses dados, pretos e pardos representavam quase 1 em cada 4 dos brasileiros hospitalizados com Síndrome Respiratória Aguda Grave $(23,1 \%)$, mas chegavam a 1 em cada 3 entre os mortos por COVID-19, o que equivale a 32,8\% (G1, 2020a). A pandemia escancara as mazelas de uma sociedade racista, classista e machista. Na fase inicial da pandemia, os primeiros casos apareceram entre as pessoas mais ricas, na sua maioria eurodescendentes. De acordo com o portal de notícias $G 1$, o primeiro caso de infecção pelo novo Coronavírus no Brasil foi de um "Homem de 61 anos, residente da capital paulista, que tinha feito viagem para a Itália, foi o primeiro registro de contaminação da doença" (G1, 2020b). A contradição é que nas casas dessa elite estão as cozinheiras, as faxineiras, as babás e tantas/os outras/os trabalhadoras/es - muitas/os delas/es afrodescendentes que precisam enfrentar o sistema público de saúde, com todas as suas mazelas.

Outro ponto evidenciado é que as marcas do racismo estão nas mulheres afrodescendentes, além de serem vulneráveis às discriminações por serem mulheres. Gonzalez (2011), ao discorrer sobre as experiências das mulheres amefricanas (latino-americanas indígenas e afrodescendentes) acentuou que o reconhecimento e a conscientização das opressões ocorrem, antes de qualquer coisa, pela categoria racial e de gênero. Isso demonstra como as questões relacionadas ao gênero são intensificadas por causa 
do racismo, afinal, ambas tratam de relações de dominação. Essas mulheres trazem as marcas de gênero e raça, e outros marcadores como condições socioeconômicas, orientação sexual, idade, e por isso mesmo, não podemos dissociar essas características em grupos e/ou categorias isoladas. As discriminações, os constrangimentos e outras violências vivenciadas, especificamente por mulheres, não são compartilhadas da mesma forma por todas elas. Falamos aqui de cruzamentos, entrecruzamentos, e atravessamentos de categorias e identidades, ou seja, de intersecções.

Crenshaw (2002) explica a interseccionalidade a partir da ideia figurada de intersecção das ruas. Para isso, precisamos pensar em, pelo menos, duas ruas que se cruzam, e se entrecruzam, umas delas basicamente no sentido "Sul-Norte" e a outra "Oeste-Leste". Podemos pensar que no sentido Sul-Norte encontram-se as discriminações raciais e o sentido Oeste-Leste as discriminações de gênero e outros fatores contextuais; os carros e o tráfego são as discriminações ativas que se encontram num ponto central onde as colisões (discriminações) geralmente ocorrem. Essas colisões (violências) são de diversas ordens: gênero, racial, classe, sexualidade, dentre outras, sempre inter-relacionadas. Vivemos num contínuo atravessamento e cruzamento de identidades constituídas e/ou impostas. São estas que, também, vão alimentando as controvérsias sociocientíficas?

Como essas intersecções afetam nas vidas afetivas, profissionais, estudantis de mulheres afrodescendentes, são questões conflituosas, muitas vezes, desvalorizadas e consideradas vitimização, na internet. Nas redes sociais como o Instagram e o Twitter, em especial, mostram expressões que são comumente utilizadas, mas que, indubitavelmente, desqualificam as denúncias de machismo e racismos, quando acontecem de fato. Elas são vistas como, "mimimi; militou errado; descansa militante; eu não vi machismo/racismo; você tá exagerando; você vê problema em tudo, mas foi só uma brincadeira; você tá chato demais". Tais formas de expressões desqualificantes demonstram que a existência e consequência do racismo, machismo e outras formas correlatas de discriminação e violência ainda são desacreditadas e não possuem notoriedade. As atitudes manifestadas nessas expressões são apresentadas com tal firmeza que chega até ao ponto de culpar as próprias vítimas. Culpar vítimas é prática confortante em contextos discriminatórios. A sociedade brasileira é exemplo com legislações como a da abolição e de ideologias como a da democracia racial. Muitas das vezes, isto acontece somente para fazer parecer real o que de fato ainda não é, e nunca tinha sido antes. Nesse caso, a expressão "só para inglês ver" representa bem essa situação de fingimento e hipocrisia da sociedade brasileira.

Nesse sentido, a utilização de controvérsias sociocientíficas em salas de aula pode ajudar crianças/jovens, e até estudantes de todos os níveis e faixas etárias, a pesquisar, argumentar, escutar e dialogar de maneira coerente sobre as intersecções de raça e gênero, problematizando seus correlatos, desvelando conhecimentos até então silenciados, como a elegibilidade às cotas raciais para acesso ao ensino superior (DIAS et al., 2018) e demais conhecimentos produzidos por mulheres e homens afrodescendentes em relação às suas experiências no "fazer certo" para conseguir alguma mobilidade social, e quem sabe, entrando em consenso sobre a perversidade dessas configurações opressoras, possibilitando assim, a produção e reconhecimento de respostas que consigam validar a sua existência. Com isso, poder ajudar a entender o funcionamento-malefício, e a partir disso, tentar romper com as armadilhas do racismo e machismo.

O pano de fundo das controvérsias nos campos científicos, tecnológicos e sociais está pautado no posicionamento de que há relações, muitas vezes mascaradas, entre conhecimentos científicos, as tecnologias, interesses políticos, econômicos, sociais, e logo 
culturais. Quando um tipo de conhecimento de um grupo particular, por exemplo, o europeu, é aceito como o universal e neutro, a questão não é somente epistemológica, é de poder em todas as esferas das relações entre grupos culturais/nacionais. O reconhecimento desta situação fez surgir o chamado Science and Technology Studies Group (Grupo de Estudos das Ciências e Tecnologia), com interesse em viabilizar novas ideias e conhecimentos referentes aos modos dos povos e países latinos no tocante às suas relações protagonistas com o conhecimento e a tecnologia. A postura não é o descarte irrestrito de conhecimentos estrangeiros já estabelecidos visando atender as necessidades locais, mas aproveitar o que existe no contexto local também, para possibilitar produções conjuntas, mais que híbridas, deixando em aberto espaços para outras criações e construções (MARQUES, 2014). Nas ciências sociais no Brasil, também, esta atitude não é estranha como apresentam os editores Neves, Bernardino-Costa e Gusmão (2018), num número especial sobre as Políticas do conhecimento e suas distintas narrativas, da Revista Sociedade e Estado, da Universidade de Brasília (UNB), onde há discussões envolvendo "ciência, políticas públicas e o mundo rural" em conjunto com outras produções questionadoras de conhecimentos estabelecidos, controvérsias sociocientíficas que serviriam de oportunidades educativas.

\section{As potencialidades educativas dos espaços digitais em relação às Controvérsias Sociocientíficas}

Quando falamos de "potencialidades educativas" pensamos nas possibilidades da educação, no seu sentido amplo e diversificado, para além de instituições formais. Partimos da concepção de "educações", no plural, por compreender que a mesma não é única, mas atravessa toda a nossa vida, como já escreveu Brandão (2007, p. 8): "Ninguém escapa da educação. Em casa, na rua, na igreja ou na escola, de um modo ou de muitos todos nós envolvemos pedaços da vida com ela: para aprender, para ensinar, para aprender-e-ensinar".

Em condições de aprendizagens continuadas, colaboramos para que as educações atravessem nossas vidas, de diferentes formas e com agentes diversos, ou seja, as potencialidades educativas são inúmeras, e assim, estamos aprendendo constantemente, seja na rua, na vizinhança, na escola, no trabalho, na praça, com os amigos, na internet, lendo livros, vendo filmes, e nesses dias de pandemia, usando o telefone celular com suas potencialidades de mobilidade. Pensando nisso, a abordagem de controvérsias sociocientíficas a partir dos espaços digitais oferecidos pela internet está repleta de potencialidades educativas. Tal realidade pode ser percebida no atual contexto que vivenciamos, no caso, a pandemia da COVID-19, onde as práticas sociais e educativas foram transformadas com a ajuda das tecnologias digitais.

Ao pensar em questões assim, em particular no que tange à escolarização, mas não restrita a ela, podemos entender o pesquisador Miskolci quando escreve:

O grande desafio na educação talvez permaneça o mesmo: o de repensar o que é educar, como educar e para que educar. Em uma perspectiva não normalizadora, educar seria uma atividade dialógica em que as experiências até hoje inviabilizadas, não-reconhecidas ou, mais comumente violentadas, passassem a ser incorporadas no cotidiano escolar (do social-cultural, nosso esclarecimento), modificando a hierarquia entre quem educa e quem é educado e buscando estabelecer mais simetria entre eles de forma a se passar da educação para um aprendizado relacional e transformador para ambos. (2012, p. 51). 
Palavras assim provocam reflexões e críticas em torno das possibilidades e desafios educativos dos espaços digitais que parecem se apresentar de maneira mais subjetiva e criativa, garantindo que as/os internautas colaborem e produzam seus próprios conteúdos, isso quer dizer que as suas experiências, opiniões e narrativas são valorizadas e consumidas por alguém. Couto (2014) ressalta três características que bem sintetizam a vida na cibercultura, que são: "participar, colaborar e compartilhar". Esse caráter participativo e de conexão entre as pessoas só foi possível a partir da mudança da Web 1.0 para a Web 2.0. De acordo com levantamentos, o conceito de Web 2.0 foi usado pela primeira vez em 2004 pelas empresas O'Reilly Media e MediaLive International em uma sessão de brainstorming (atividade que explora a criatividade e produção de ideias sobre um determinado tema) numa conferência, no qual discutiram o surpreendente desenvolvimento de sites e aplicativos na Web, proporcionando uma nova geração de comunidades e serviços, assim, Tim O'Reilly, responsável pela primeira empresa, argumentou que a Web 2.0 encara a internet como plataforma e a principal regra para se obter sucesso é o desenvolvimento de aplicativos e quanto mais utilizados pelas pessoas mais se aproveitaria o trabalho colaborativo (O'REILLY, 2005).

Santos explica que na Web 1.0, os sites eram grandes "repositórios de conteúdos produzidos por especialistas da informática" (2015, p. 136), cabia ao usuário/a apenas navegar, assistir e copiar, o que não possibilitava a interação e produção de conteúdo. Por outro lado, na Web 2.0, foi possível a criação de redes e mídias sociais, como o Facebook, Twitter, Instagram, YouTube, Blogs entre outros, garantindo maior interação entre as/os internautas, bem como, o compartilhamento de suas experiências e narrativas; uma cultura dialógica em expansão permanente, cada vez mais inclusiva que excludente, no tocante às controvérsias vigentes.

Embora a internet tenha sido criada para ser um espaço dialógico e inclusivo, também encontramos tentativas de exclusão, violência e silenciamentos. Mangueira e Fraga (2018) nos chamam atenção sobre isso na matéria WEB registra cerca de 100 mil casos de racismo em uma década, onde apontaram um relatório divulgado, em 2017, pela Norton Cyber Security, evidenciando que o racismo ocupou primeiro lugar do ranking como crime virtual mais popular, sendo o Facebook, o site com maior registro de denúncias. Isso quer dizer que a possibilidade de interação e compartilhamento de pensamento faz com que as pessoas transportem os preconceitos e racismos da vida real para as telas dos celulares e computadores. Esses são desafios apresentados na utilização da Web 2.0 que precisam ser encarados de maneira crítica e coerente. E assim, pensamos que, discutir e problematizar comentários racistas e machistas oriundos dos espaços digitais pode servir como possibilidades educativas no trato das CSC. Não é possível negar esse tipo de prática; pois ela claramente denuncia a sociedade racista e machista em que vivenciamos e que ajudamos a construir.

Por outro lado, da internet enquanto espaço de criação, compartilhamento, colaboração, discussão, exposição, interação em um contexto educativo, emerge uma linguagem própria e oportuniza ensinamentos e aprendizagens contínuas, potencializando educações plurais e para a diversidade. Os espaços digitais comportam diálogos em rede, conectado e atravessado por diferentes linhas ordenadas e desordenadas, possibilitando "ondas de fortalecimento", principalmente de grupos historicamente excluídos e silenciados, como é o caso das mulheres e homens afrodescendentes. Estes, que de maneira criativa e desafiadora, vêm expondo e criando temas e conteúdos a partir de suas narrativas e experiências para discutir e denunciar os racismos, machismos, homofobias e outros fatores de exclusões sociais ilógicas e injustas. 
Essas considerações corroboram para os dizeres de Santos quando menciona que "[...] a cibercultura, em sua fase atual, potencializa as práticas pedagógicas baseadas em fundamentos valorizados, como autonomia, diversidade, diálogo e democracia” (2015, p. 137). Se a cibercultura, traduzida em Web 2.0, pode incrementar práticas pedagógicas sistematizadas, então é possível inferir que essa educação em rede possui um ambiente propício para dialogar, pesquisar e discutir também sobre CSC, em especial, aquelas relacionadas às intersecções entre raça e gênero, e outras categorias semelhantes. Nesse sentido, indagamos: Quais as potencialidades educativas da utilização da Web 2.0 na discussão de controvérsias sociocientíficas?

Sobre isso, podemos recorrer a pesquisas já realizadas em que tratam das potencialidades educativas em espaços digitais como blogs, Wiki, YouTube e outros. A pesquisa de Santo e Reis (2013) intitulada: Utilização de blogues na discussão de controvérsias sociocientíficas na disciplina de ciências da natureza tinha como objetivo avaliar as potencialidades educativas da discussão de CSC na disciplina de Ciências da Natureza, utilizando blogs. Neste estudo participaram 26 alunos de uma turma do quinto ano de escolaridade (alunos com 11 anos de idade), na cidade de Lisboa, em Portugal. De maneira sucinta, a pesquisa em questão criou blogs para que fosse discutida a "pesca de arrasto em profundidade", levando as/os alunas/os a questionarem as motivações para esse tipo de técnica e suas possíveis consequências para o meio ambiente.

Ao final da pesquisa, Santo e Reis concluíram que o blog “[...] é um recurso educativo gratuito que estimula a curiosidade, promove o desenvolvimento do trabalho colaborativo, permitindo aos alunos colaborarem na identificação e resolução de problemas" (2013, p. 22). Ele também garante que as/os alunas/os trabalhem em conjunto e se sintam motivadas/os para pesquisar e produzir seu próprio conteúdo. Os autores ainda ressaltam que o blog é "[...] simples, motivador, de utilização intuitiva, sendo por isso fácil de utilizar e implementar, tornando os conteúdos acessíveis em qualquer parte do mundo [...]” (SANTO; REIS, 2013, p. 22).

Boakari e Souza (2019), no estudo denominado Mulheres afrodescendentes e espaços virtuais: para visibilizar aberturas epistemológicas, discutem algumas respostas empreendidas por um grupo de mulheres brasileiras afrodescendentes em espaços digitais, como no YouTube e Instagram. Essa iniciativa teve como propósito evidenciar os lugares de fala dessas mulheres, suas agencias subjetivas e subjetividades contextualizadas. No estudo em questão, foram citadas algumas mulheres afrodescendentes como Gabi Oliveira, Maíra Azevedo, Ana Paula Xongani, Nátaly Neri, Naíse Caldas que se utilizam desses dois espaços digitais para provocar fissuras nos silenciamentos e discriminações interseccionais entre raça e gênero. Todas, de diferentes formas, produzem conteúdos para abordar assuntos relacionados à estética, à construção de identidade, ao racismo, ao machismo, ao empreendedorismo, ao feminismo, à intolerância religiosa, dentre outros temas polêmicos (educativos) contemporâneos. Elas ajudam outras mulheres afrodescendentes e de outros pertencimentos raciais e descendências a problematizarem e conhecerem a realidade das mulheres descendentes de africanos/as, proporcionando ondas de fortalecimento de existência e resistência.

Dessa forma, essas mulheres ao expor suas experiências e discutirem os temas relacionados às intersecções entre raça e gênero estão produzindo conteúdos e narrativas que são consumidas e ressignificadas por outras mulheres e também por homens, existindo uma linha fina e tênue de produzir, consumir e ampliar, disseminando em rede, muitas vezes entrelaçadas e interconectadas. Efeito multiplicador em forma geométrica. Bonilla e Pretto 
(2015) conseguem sintetizar como o compartilhamento, participação, produção e interação ocasionadas pela internet aproxima as pessoas e os conhecimentos, tornando-os não apenas espectadores das vidas dos outros, mas protagonistas de suas próprias vidas “[...] a proliferação festiva das narrativas pessoais é um modo fascinante de compartilhar conhecimentos, promover e solidificar as pedagogias das conexões, exaltar sinergias, encontros e criativos modos solidários de viver a cibercultura" (BONILLA; PRETTO, 2015, p. 49). Modos diferentes de ensinar e aprender, viabilizando vivências e convivências em sociedade cada vez mais interconectada e "interinfluenciável", como as relações e inter-relações entre as ciências, tecnologias, culturas e sociedades apontadas nas produções organizadas por Conrado e Nunes-Neto (2018) e Robaina, Hoffmann, Duso, Reis e Pérez (2020). São inúmeras as possibilidades educativas, por isso mesmo, insistimos em dizer que espaços digitais como o Instagram, Facebook, YouTube, podem ser utilizados como recurso educativo para questionar e discutir controvérsias sociocientíficas.

Para exemplificar as potencialidades educativas nos espaços digitais destacamos o YouTube, uma plataforma digital de compartilhamento de vídeos, criado em 2005, sem muito alarido, por Chad Hurley, Steve Chen e Jawed Karim, ex-funcionários do site de comércio on-line PayPal (BURGESS et al., 2009). Atualmente, essa plataforma digital vem alcançando atenção e interesse entre as/os internautas, pois possibilita que algumas pessoas consideradas comuns e anônimas, através de divulgações/postagens de assuntos interessantes e úteis, sejam transformadas em protagonistas de suas próprias vidas, como afirmam Mota e Pedrinho: "O fascínio da imagem atinge seu ápice quando nós somos a própria mensagem” (2009, p. 09).

Sobre a youtuber Gabi Oliveira, do Rio de Janeiro, sabemos que é formada em Comunicação Social (UERJ) e responsável pelo canal DePretas. Segundo dados mais recentes, em janeiro de 2021, o canal registrou 629 mil inscritos. Os temas abordados pela Gabi Oliveira estão relacionados às questões raciais e a estética da mulher afrodescendente. Dentre seus vídeos, destacamos aquele intitulado, Negra de pele escura part. Soul Vaidosa, postado no ano de 2016, com 51.832 (cinquenta e um mil oitocentos e trinta e duas) visualizações, 6,3 mil curtidas e apenas 27 não curtidas. Nesse vídeo, juntamente com a youtuber Xan Ravelli do canal Soul Vaidosa, elas conversam sobre as experiências de ser mulher afrodescendente de "cor retinta" numa sociedade racista e machista.

As duas youtubers destacam algumas de suas experiências vexatórias, pela condição de ser mulher afrodescendente com pele escura, cabelos crespos, nariz largo, características historicamente inferiorizadas e desvalorizadas, como as que se seguem: é muito difícil falar sobre isso, pois ainda existem "feridas que não foram cicatrizadas"; desconheciam os ranços racistas e machistas das piadas e situações constrangedoras vivenciadas na infância e adolescência, situações que lhes levavam a acreditar que o problema estava com elas mesmas, o que faz gerar prejuízo na construção valorativa de suas identidades; a falta de conversa sobre essas questões fizeram com que elas se sentissem feias e incapazes. A partir da tomada de consciência desse viés e de sua significação na formação deformada de sua identidade, chegaram à conclusão sobre a importância de falar dessas experiências. E como a internet se faz um importante meio de discussão de situações discriminatórias que ressaltam a necessidade de garantir oportunidade para que outras meninas e mulheres possam discutir sobre esses assuntos e para que se sintam reconhecidas, representadas e fortalecidas (OLIVEIRA, 2016).

Então, a partir deste vídeo algumas possibilidades educativas podem ser fomentadas e discutidas. Pontuamos pelo menos três aspectos e/ou categorias que poderiam servir de disparadores de discussão e problematização. A primeira trata-se do reconhecimento das 
identidades como plurais, a segunda, a construção do racismo e do machismo e a terceira a importância da representatividade. Tais categorias poderiam ajudar na busca de novas pesquisas, a fim de entender as construções históricas e culturais da sociedade brasileira, principalmente no que se refere às intersecções entre raça e gênero vivenciadas por mulheres afrodescendentes. Além disso, a criação de um canal no YouTube para discussão dessas categorias, poderia fomentar a pesquisa, a criação, a colaboração, o diálogo, e a tentativa de resolver problemas/situações traduzidas em possibilidades educativas, que poderiam ser realizadas nas escolas, incentivando a autoria/produção tanto do educando como do/a professor/a, estabelecendo assim, aprendizagens contínuas em rede.

Outro canal no YouTube que vem proporcionando discussões sobre os racismos e machismos é o Afro e Afins da youtuber Nátaly Neri, que reside na cidade de São Paulo, o canal foi iniciado quando ela cursava Ciências Sociais, há quatro anos atrás, desde então, já possui 742 mil inscritos, verificado em janeiro de 2021. No canal são abordados assuntos como raça, gênero, sociedade, sustentabilidade entre outros. Dentre os vídeos, escolhemos o intitulado Empoderamento estético e consciência racial publicado em 2017, com 69.676 (sessenta e nove mil seiscentos e setenta e seis) visualizações, 11 mil curtidas, 90 não curtidas e 609 comentários. No vídeo escolhido, Neri discorre sobre como se descobriu "negra" (nomenclatura que a youtuber se referiu no vídeo) e a importância do empoderamento estético para a construção de suas identidades e consciência racial.

Nátaly Neri narrou suas experiências desde criança em relação ao seu pertencimento racial e disse que seus pais, mesmo não sendo militantes, enfatizavam que a mesma era negra, explicando a existência do racismo na sociedade. Sua mãe, ela registrou, dizia que a realidade não era um "conto de fadas" quando se é negra/o. Algumas pessoas perguntavam a Neri se o seu reconhecimento racial, desde a infância, facilitou a construção de suas identidades e consciência racial. Era como se ela estivesse em cima do muro e a qualquer momento poderia cair no lado dos/as "negros/as" ou do lado dos/as "brancos/as" e ela queria cair neste último lado, como enfatizou: "Por que não viver uma vida de privilégios?" A youtuber ressaltou que essa situação é algo específico de mulheres que possuem o traço da miscigenação mais aparente, apontando para sua pele que não é retinta. O momento chave da construção de sua consciência racial foi quando começou a trabalhar, por volta dos 15 anos de idade, e teve a oportunidade de participar de um curso sobre tranças e dreads. Foi nessa experiência, que ela decidiu não mais alisar os cabelos, pois ao aprender os significados desses penteados, a youtuber se conectou com sua ancestralidade, passou a se ver de maneira valorativa, sem julgamentos negativos e a cuidar do seu cabelo crespo como algo bonito. Terminou o vídeo enfatizando que a discussão sobre o empoderamento estético pode ser um disparador para entender e problematizar a realidade das mulheres brasileiras afrodescendentes e que a discussão não pode ficar apenas na questão da estética, precisando ser ampliada (NERI, 2017).

Como no vídeo da Gabi Oliveira, descrito acima, podemos discorrer sobre algumas possibilidades educativas no vídeo da Nátaly Neri. Destacamos pelo menos três possibilidades-meios a partir desse vídeo: a primeira seria a discussão sobre a construção das identidades, partindo das seguintes indagações: Qual a sua história? Qual a história da sua família? O que ela diz sobre você? Outro ponto a ser discutido é o processo de miscigenação brasileiro, onde as histórias das famílias poderiam suscitar diversas narrativas. Uma terceira alternativa é decorrente das seguintes provocações: Como você se vê? Você gosta de como você se vê? Numa tentativa de construir um ambiente respeitoso e um espaço de acolhimento e fortalecimento para a construção de uma autoestima positiva. As alternativas apresentadas aqui levam para a importância de falar de si, de narrar as próprias experiências e conhecer sua 
história, elementos que não são fomentados pela escola que temos. Dessa forma, percebemos que o YouTube proporciona aprender com as narrativas de si além de incentivar a produção de conteúdo em diversos formatos. Situações em que esta mídia viabiliza ser espaço, instrumento educativo e elemento estruturante de categorias constituindo controvérsias sociocientíficas.

Os espaços digitais, oportunizados pela Web 2.0, em especial o YouTube, parecem ser terrenos férteis para a discussão das interseccionalidades entre raça e gênero como controvérsia sociocientífica, nos quais, as/os alunas/os podem compartilhar e discutir de forma fundamentada as consequências dos silenciamentos e discriminações vivenciadas por mulheres afrodescendentes e mais do que isso, podem ser protagonistas de suas próprias histórias, ao narrar suas experiências e produzir narrativas em combate a essa realidade através de vídeos. Como instrumento e recurso pedagógico, o YouTube visa o acesso à informação de maneira descontraída e fácil para muitas pessoas internautas. A abordagem das CSC por meio dos espaços digitais possui uma função educativa e pedagógica muito significativa, pois proporcionam possibilidades de ensino-aprendizagem autônoma, participativa e proveitosa para a diversidade na sua rica multiplicidade. As potencialidades educativas podem ser numerosas, diversificadas, multiplicadas e continuamente estendidas para serem mais relevantes, por isso, necessitam ser fomentadas, ampliadas e discutidas para provocar mudanças nos silenciamentos, discriminações e pedagogias tradicionais.

\section{Conexões, colaboração e coletivo: algumas considerações inconclusivas}

Couto quando enfatiza que na "[...] era das conexões as pessoas aprendem trabalhando em conjunto, colaborando umas com as outras, com os professores e também entre si" (2014, p. 62), três palavras parecem se sobressaltar - "conexões", "colaboração" e "coletivo". Características que atravessam os espaços digitais na abordagem de controvérsias sociocientíficas. Mais do que isso, podem ser modos de educar diferenciados e criativos, perpassados pelo diálogo-participação-coletividade e subjetividades com respeito mútuo e permanente como mostram os resultados da pesquisa desenvolvida por Oliveira e Amaral (2020) ao usar o Whatsapp para ensinar a matemática para estudantes jovens.

Prosseguindo, apresentamos características que também descrevem essa educação em rede que discutimos até aqui. Essa educação em rede pode ser associada a uma educação problematizadora anunciada por Freire, quando enuncia que "[...] o educador já não é o que apenas educa, mas o que, enquanto educa, é educado, em diálogo com o educando que, ao ser educado, também educa" (1987, p. 78). Os papéis de professor/a e aluno/a se cruzam, se atravessam, são continuamente trocados, ou seja, uma educação em que todos/as trabalham em conjunto, "colaborando umas com as outras". Freire (1987) ensina que uma educação problematizadora tem caráter reflexivo e procura constantemente desvelar a realidade. Refletir e desvelar as realidades podem ser atitudes encorajadas e proporcionadas nos espaços digitais e também na discussão de controvérsias sociocientíficas junto a crianças, jovens, adultos e idosos.

Diante disso, retomemos a pergunta central desse estudo: "Quais potencialidades educativas podem ser encontradas na utilização da Web 2.0, na discussão de controvérsias sociocientíficas, em especial, nas interseccionalidades entre raça e gênero?" Não gostaríamos de elaborar respostas fechadas e únicas, mas, fornecer pistas e provocações referentes às potencialidades educativas da $W e b 2.0$ em relação às questões de raça e gênero, como elencado a seguir: 
a) incentiva olhar para si mesmo, para a sua história, perspectivando construir/evidenciar as próprias narrativas;

b) oportuniza a curiosidade, a pesquisa, visando buscar outros conhecimentos;

c) fomenta o trabalho colaborativo e o trabalho autoral;

d) estimula o diálogo e escuta ativa, nutrindo o respeito às diferenças;

e) proporciona aprender de maneira diferenciada, leve, pessoal e descontraída ao ter acesso e domínio dessas tecnologias;

f) possibilita materiais em diversos formatos com informações relevantes sobre as interseccionalidades entre raça e gênero, bem como, tocante a outros temas semelhantes;

g) permite desvelar a realidade, construindo pensamento crítico;

h) faz com que as controvérsias sociocientíficas sejam encaradas como problemas sociais, preocupações de toda a sociedade.

Com os pontos elencados acima, enfatizamos e priorizamos uma educação coletiva e humana que vise à fomentação e o reconhecimento dos conhecimentos historicamente excluídos, como forma de "refletir e desvelar a realidade", sendo assim precisamos aprender com o outro, no nosso caso, com as experiências de mulheres afrodescendentes. Freire (1987) informa que o fenômeno do diálogo é revelado através da palavra, e a mesma implica duas dimensões, ação e reflexão, que atuando de maneira conjunta torna-se práxis, e por isso, menciona a relevância de dizer a palavra com o outro, “[...] ninguém pode dizer a palavra verdadeira sozinho, ou dizê-la para os outros, num ato de prescrição, com o qual rouba a palavra aos demais" (FREIRE, 1987, p. 44). O diálogo com o outro pode ser proporcionado a partir das redes e mídias sociais, principalmente quando se discute controvérsias sociocientíficas.

Enquanto essas mídias e esses canais como instrumentos de comunicação, troca compreensível de significados contextualizados, podem, também, levar ao fechamento das vias para o diálogo e outras trocas humanizadoras. Estes mesmos equipamentos sociais, por sua vez, poderiam ser aplicados para promover exclusões e fechar fronteiras entre grupos e culturas. Ou seja, as redes sociais podem abrir caminhos para interações positivas e relações de exploração e dominação. Situações onde as controvérsias sociocientíficas fortalecem políticas e práticas que humanizam, quando há outras que funcionam contra a humanidade dos seres humanos envolvidos.

Com isso, queremos dizer que as interseccionalidades relacionadas às categorias de raça e gênero são questões e fenômenos que merecem atenção, em especial, das/os professoras/es, porque ajudam a descrever, explicar, exemplificar, refletir, problematizar e desvelar a realidade em que vivenciamos. Precisamos de meios, cada vez mais adequados e eficazes, para discutir, de forma coerente e embasada, as discriminações e vulnerabilidades enfrentadas pelas mulheres em sociedades contemporâneas, especialmente quando são pessoas afrodescendentes. Bem como, necessitamos de respostas educativas capazes de romper com as armadilhas dos mascaramentos, desvios cognitivos, silenciamentos e discriminações.

A abordagem de controvérsias sociocientíficas em espaços digitais está repleta de potencialidades educativas, pois ajuda mais objetivamente a enxergar todas/os como protagonistas da própria existência, potencializando mais força e autonomia para provocar problematizações e mudanças conscientes num contexto racista e machista como a sociedade brasileira. Sociedade na qual as controvérsias sociocientíficas giram principalmente em torno 
de atitudes e práticas difíceis de entender, especialmente quando se reflete sobre as violências que continuam marcando a fábrica da cultura brasileira. Com as mídias e novas tecnologias em expansão, com mais acessibilidade e melhores competências tecnológicas, as controvérsias em torno das realidades cotidianas estão se tornando questões de um maior número de pessoas de diversos grupos sociais. Controvérsias sociocientíficas que estão sendo transformadas em problemas sociais e preocupações de toda a sociedade.

\section{Referências}

BOAKARI, Francis Musa; SOUZA, Emanuella Geovana Magalhaes de. Mulheres afrodescendentes e espaços virtuais: para visibilizar aberturas epistemológicas. Fórum Identidades, Itabaiana-SE, v. 29, n. 01, p. 231-246, 2019. Disponível em: https://snsufs.revistas.ufs.br/index.php/forumidentidades/article/view/12363. Acesso em: 20 dez. 2019.

BONILLA, Maria Helena; PRETTO, Nelson de Luca. Movimentos colaborativos, tecnologias digitais e educação. Em Aberto, Brasília, v. 28, n. 94, p. 23-40, 2015. Disponível em: https://doi.org/10.24109/2176-6673.emaberto.28i94.1666. Acesso em: 16 jun. 2019.

BRANDÃO, Carlos Rodrigues. O que é educação? 1. ed. São Paulo: Brasiliense, 2007.

BRASIL. Ministério da Saúde. Sobre a doença, [2020]. Disponível em: https://coronavirus.saude.gov.br/index.php/sobre-a-doenca. Acesso em: 04 jun. 2020.

BURGESS, Jean et al. YouTube e a Revolução Digital: como o maior fenômeno da cultura participativa transformou a mídia e a sociedade. São Paulo: Aleph, 2009.

CARNEIRO, Aparecida Sueli. A construção do outro como não-ser como fundamento do ser. 2005. Tese (Doutorado em Educação) - Universidade de São Paulo, São Paulo, 2005. Disponível em: https://negrasoulblog.files.wordpress.com/2016/04/a-construc3a7c3a3o-do-outro-como-nc3a3 o-ser-como-fundamento-do-ser-sueli-carneiro-tese1.pdf. Acesso em: 12 dez. 2017.

COLling, Ana Maria. A construção histórica do corpo feminino. Caderno Espaço Feminino, Uberlândia, v. 28, n. 2, p. 180-199, 2015. Disponível em: http://200.19.146.79/index.php/neguem/article/view/34170. Acesso em: 17 maio 2020.

CONRADO, Dália Melissa; NUNES-NETO, Nei. (orgs.). Questões sociocientíficas: fundamentos, propostas de ensino e perspectivas para ações sociopolíticas. Salvador: EDUFBA, 2018.

CORONAVÍRUS é mais letal entre negros no Brasil, apontam dados do Ministério da Saúde. G1 Bem estar. 11 abr. 2020a. Disponível em: https://g1.globo.com/bemestar/coronavirus/noticia/2020/04/11/coronavirus-e-mais-letal-entrenegros-no-brasil-apontam-dados-do-ministerio-da-saude.ghtml. Acesso: 03 jan. 2021.

COUTO, Edvaldo Souza. Pedagogias das conexões: Compartilhar conhecimentos e construir subjetividades nas redes sociais digitais. In: PORTO, Cristiane; SANTOS, Edméa (org.). 
Facebook e Educação: publicar, curtir, compartilhar. Campina Grande: EDUEPB, 2014. p. 47-65.

CRENSHAW, Kimberlé. Documento para o encontro de especialistas em aspectos da discriminação racial relativos ao gênero. Estudos feministas, Florianópolis, v. 10, n. 1, p. 171-188, 2002. Disponível em: http://dx.doi.org/10.1590/S0104-026X2002000100011. Acesso em: 10 jan. 2018.

DAMATTA, Roberto. O que faz o brasil, Brasil? Rio de Janeiro: Rocco, 1986.

DIAS, Thiago Leandro da Silva; FERNANDES, Kelly Meneses; ARTEAGA, Juanma Sanchez; SEPÚLVEDA, Claudia. Cotas raciais, genes e política: uma questão sociocientífica para o ensino de ciências. In: CONRADO, Dália Melissa: NUNES-NETO, Nei. (orgs.). Questões sociocientíficas: fundamentos, propostas de ensino e perspectivas para ações sociopolíticas. Salvador: EDUFBA, 2018, p. 303-324.

DUARTE, Fernando. Amputações, estupros e assassinatos: o horror do Congo Belga. AH Aventuras na História, [S. l.], 16 jan. 2020. Disponível em:

https://aventurasnahistoria.uol.com.br/noticias/reportagem/genocidio-africa-congo-belga-leop oldo-ii.phtml. Acesso em: 14 mar. 2020.

FLICK, Uwe. Introdução à metodologia da pesquisa: um guia para iniciantes. 1. ed. Porto Alegre: Penso, 2013.

FREIRE, Paulo. Pedagogia do oprimido. 17. ed. Rio de Janeiro: Paz e Terra, 1987.

GOMES, Nilma Lino. Trabalho e justiça social a questão racial e o novo coronavírus no

Brasil. [S. 1.]: Fundação Friedrich-Ebert-Stiftung, jun. 2020. Disponível em:

http://library.fes.de/pdf-files/bueros/brasilien/16315.pdf. Acesso em: 03 jan. 2021.

GONZALEZ, Lélia. Por um feminismo afrolatinoamericano. São Paulo: Caderno de Formação Política do Círculo Palmarino, 2011. Disponível em:

https://edisciplinas.usp.br/pluginfile.php/271077/mod_resource/content/1/Por\%20um\%20fem inismo\%20Afro-latino-americano.pdf. Acesso em: 12 jan. 2021.

IBGE - Instituto Brasileiro de Geografia e Estatística (Brasil). Desigualdades Sociais por Cor ou Raça no Brasil. Rio de Janeiro: Instituto Brasileiro de Geografia e Estatística, 2019. Disponível em:

https://biblioteca.ibge.gov.br/index.php/biblioteca-catalogo?view=detalhes\&id=210168. Acesso em: 12 jan. 2021.

KRUPCZAK, Carla; AIRES, Joanez Aparecida. Controvérsias sociocientíficas: uma análise da produção acadêmica brasileira. VIDYA, Santa Maria, v. 39, n. 1, p. 277-290, 2019.

Disponível em: https://periodicos.ufn.edu.br/index.php/VIDYA/article/view/2654. Acesso em: 06 mar. 2020.

KRUPCZAK, Carla; AIRES, Joanez Aparecida; REIS, Pedro Guilherme Rocha dos. Controvérsias sociocientíficas: análise comparativa entre Brasil e Portugal. Revista de Educação em Ciências e Matemática, Amazônia, v.16, n. 37, p. 89-105, 2020. Disponível 
em: https://www.periodicos.ufpa.br/index.php/revistaamazonia/article/view/8584/6691\#. Acesso em: 16 maio 2021.

LATOUR, Bruno. Jamais fomos modernos: ensaio de antropologia simétrica. 1. ed. Rio de Janeiro: Editora 34, 1994.

MACEDO, José Rivair (org.). Desvendando a história da África. Ebook. Porto Alegre: UFRGS, 2008. Disponível em:

https://static.scielo.org/scielobooks/yf4cf/pdf/macedo-9788538603832.pdf. Acesso em: 21 maio 2020.

MANGUEIRA, Giovane; FRAGA, Leonardo. WEB registra cerca de 100 mil casos de racismo em uma década. Portal Geledés, 13 jun. 2018. Disponível em:

https://www.geledes.org.br/web-registra-cerca-de-100-mil-casos-de-racismo-em-uma-decada/ Acesso em: 18 maio 2020.

MARQUES, Ivan da Costa. Ontological politics and Latin American local knowledge. In: MEDINA, Eden; MARQUES, Ivan da Costa; HOLMES, Christina. Beyond imported magic: essays on Science, Technology, and Society in Latin America. Cambridge, Massachusetts, USA: MIT Press, 2014. p. 85-110.

MARTINS, Alejandra. Por que a Alemanha não se desculpou até hoje pelo primeiro genocídio do século 20. BBC-Mundo, 10 jan. 2017. Disponível em:

https://www.bbc.com/portuguese/internacional-38554223. Acesso em: 14 mar. 2020.

MOTA, Maurício; PEDRINHO, Suzana. Conciliando pensar e fazer com o YouTube, ou "a fábrica de presentes". In: BURGESS, Jean et al. (org.). YouTube e a Revolução Digital: como o maior fenômeno da cultura participativa transformou a mídia e a sociedade. São Paulo: Aleph, 2009, p. 07-10.

MIGNOLO, Walter D. El pensamiento decolonial: desprendimiento y apertura. Un manifesto. In: CASTRO-GÓMEZ, Santiago; GROSFOGUEL, Ramón (org). El giro decolonial: reflexiones para una diversidad epistémica más allá del capitalismo global. Bogotá: Siglo del Hombre Editores; Universidad Central, Instituto de Estudios Sociales Contemporáneos y Pontificia Universidad Javeriana, Instituto Pensar, 2007.

MISKOLCI, Richard. Teoria queer: um aprendizado pelas diferenças. Belo Horizonte: Autêntica, 2012.

NERI, Nátaly. Empoderamento estético e consciência racial. Canal Afros e Afins, 18 nov. 2017. 1 vídeo (13min35seg). Disponível em:

https://www.youtube.com/watch?v=iylniabCleQ\&t=1s. Acesso em: 15 maio 2020.

NEVES, Fabrício Monteiro; BERNARDINO-COSTA, Joaze; GUSMÃO, Luís Augusto Sarmento Cavalcanti de. Políticas do conhecimento e suas distintas narrativas. Revista Sociedade e Estado, Brasília, v. 33, n.1, p. 07-12, 2018. Disponível em:

https://doi.org/10.1590/s0102-69922018330editorial. Acesso em: 16 maio 2020. 
OLIVEIRA, Gabi. Negra de pele escura part. Soul Vaidosa. Canal DePretas, 10 jun. 2016. 1 vídeo (13min47seg). Disponível em: https://www.youtube.com/watch?v=z0wGdYZ7zLc. Acesso em: 15 maio 2020.

OLIVEIRA, Terezinha Marisa Ribeiro de; AMARAL, Carmen Lúcia Costa. O uso do aplicativo Whatsapp como recurso didático: uma experiência no ensino fundamental anos finais. \#Tear: Revista de Educação Ciência e Tecnologia, v. 09, n. 01, p. 01-12, 2020. Disponível em: https://periodicos.ifrs.edu.br/index.php/tear/issue/view/94. Acesso: 12 maio 2021.

O'REILLY, Tim. What Is Web 2.0 - Design Patterns and Business Models for the Next Generation of Software. O'Reilly Publishing, 2005. Disponível em:

http://www.oreilly.com/pub/a/web2/archive/what-is-web-20.html. Acesso em: 04 jul. 2020.

PRIMEIRO caso confirmado de Covid-19 no Brasil ocorreu em SP e completa seis meses nesta quarta. G1 Bem Estar, 26 ago. 2020b. Disponível em:

https://g1.globo.com/bemestar/coronavirus/noticia/2020/04/11/coronavirus-e-mais-letal-entrenegros-no-brasil-apontam-dados-do-ministerio-da-saude.ghtml. Acesso: 03 jan. 2021.

QUIJANO, Aníbal. Colonialidade do poder, eurocentrismo e América Latina. In: LANDER, Edgardo. (org.). A colonialidade do saber: eurocentrismo e ciências sociais - perspectivas latino-americanas. Buenos Aires: CLASCO, 2005. p. 117-142. Disponível em: https://edisciplinas.usp.br/pluginfile.php/2591382/mod_resource/content/1/colonialidade_do_ saber_eurocentrismo_ciencias_sociais.pdf. Acesso em: 10 jan. 2018.

REIS, Pedro. Uma iniciativa de desenvolvimento profissional para a discussão de controvérsias sociocientíficas em sala de aula. Revista Interacções, Lisboa, n. 4, p. 64-107, 2006. Disponível em: https://doi.org/10.25755/int.321. Acesso em: 18 mar. 2020.

ROBAINA, José Vicente Lima; HOFFMANN, Marilisa Bialvo; DUSO, Leandro; REIS, Pedro; PÉREZ, Leonardo Fabio Martínez. Controvérsias sociocientíficas na perspectiva interdisciplinar de formação de professores. \#Tear: Revista de Educação, Ciência e Tecnologia, v. 09, n. 01, 2020. Disponível em:

https://periodicos.ifrs.edu.br/index.php/tear/issue/view/94. Acesso: 12 maio 2021.

ROSE, Diana. Análise de imagens em movimento. In: BAUER, Martin W.; GASKELL, George (ed.). Pesquisa qualitativa com texto imagem e som: um manual prático. 2. ed. Petrópolis, RJ: Vozes, 2002.

SANTO, Marta Espírito; REIS, Pedro. Utilização de blogues na discussão de controvérsias sociocientíficas na disciplina de Ciências da Natureza. Caderno Pedagógico, Lajeado, v. 10, n. 1, p. 9-24, 2013. Disponível em:

http://www.univates.br/revistas/index.php/cadped/article/view/868. Acesso em: 04 fev.2020.

SANTOS, Boaventura de Sousa. Para além do pensamento abissal: das linhas globais a uma ecologia de saberes. Novos Estudos: CEBRAP, São Paulo, n. 79, p.71-94, 2007. Disponível em: http://dx.doi.org/10.1590/S0101-33002007000300004. Acesso em: 10 fev. de 2017. 
SANTOS, Edméa. A mobilidade cibercultural: cotidianos na interface educação e comunicação. Em Aberto, Brasília, v. 28, n. 94, p. 134-145, 2015. Disponível em: https://doi.org/10.24109/2176-6673.emaberto.28i94.1675. Acesso em: 10 fev. 2020.

SILVEIRA, Evanildo da. Em reação a negacionismo, pesquisadores levam 'ciência descomplicada' às redes sociais. BBC News Brasil, 20 abr. 2021. Disponível em: https://www.bbc.com/portuguese/salasocial-56421745. Acesso em: 13 maio 2021.

TERTO, Amauri. 12 youtubers negras que estão empoderando mulheres na internet. Portal Geledés, 24 nov. 2016. Disponível em:

https://www.geledes.org.br/12-youtubers-negras-que-estao-empoderando-mulheres-na-interne t/. Acesso em: 18 maio 2020.

Recebido em fevereiro de 2021.

Aprovado em maio de 2021. 